\title{
ANALYSIS OF TRENDS IN THE DEVELOPMENT OF THE NATIONAL ECONOMY BY REGIONAL SIGN TAKING INTO ACCOUNT THE ECOLOGICAL COMPONENT
}

\author{
Kostiantyn Shaposhnykov', Yuriy Pavelko²
}

\begin{abstract}
The purpose of this work is to study the development of the national economy in recent years taking into account the environmental component. It is proved that providing conditions for long-term economic growth is the primary task of macroeconomy of any country. Unstable development of the national economy in recent decades accompanied by prolonged crises, as well as a slow path of reforming all spheres of life on the way to building a democratic society with a developed market economy cause constant attention of domestic scientists to this direction. Methodology. The results of environmental protection measures are classified, based on the practical use of modern economic and mathematical methods and models. Results. It is proved that when using these methods, the results of law enforcement measures can be divided into the following groups: in the conditions of positive rates of economic development, the volumes of atmospheric emissions of pollutants and carbon dioxide had a negative dynamics. This scenario of environmental and economic efficiency is the most desirable; positive growth rates of fresh water use are inferior to GDP growth rates, the rates of waste generation and water abstraction exceed the dynamics of GDP growth. This scenario is the least acceptable, as not only environmental damage is increasing in absolute terms, but environmental performance is also deteriorating. Practical implications. The period of 2015-2018 was chosen for research as it was characterized by the resumption of gradual economic growth in most sectors of the economy after the deep crisis of 2014. The available data of the State Statistics Service of Ukraine for 2019 has not currently contained complete information on volumes anthropogenic impact. The leaders of regional development in terms of GRP growth in 2015-2018 were Volyn (+ 5.72\%), Kyiv (+ 5.66\%) and Zhytomyr (+ 5.00\%) regions. In contrast, the most depressed regions with negative economic growth rates were Donetsk $(-1.86 \%)$, Luhansk (-0.84\%) and Poltava (-0.51\%) regions. In the latter region, the rate of population decline exceeded the increase in labor productivity, resulting in a decrease in performance. Value/originality of the work is the analysis of trends in the national economy taking into account the environmental component, which in contrast to the existing comes from modern experience of practical use of economic and mathematical methods, which allows to develop recommendations based on quantitative estimates.
\end{abstract}

Key words: trends in the national economy, productivity growth, the results of environmental measures, the environmental component.

Jel Classification: E42, Q01

\section{Introduction}

Ensuring the conditions for long-term economic growth is a top priority of macroeconomy of any country. Unstable development of the national economy in recent decades accompanied by prolonged crises, as well as a slow path of reforming all spheres of life on the way to building a democratic society with a developed market economy cause constant attention of domestic scientists to this range. Factors and prerequisites for economic

Corresponding author:

${ }^{1}$ Black Sea Research Institute of Economy and Innovation, Ukraine. ORCID: https://orcid.org/0000-0003-0640-9934

${ }^{2}$ Black Sea Research Institute of Economy and Innovation, Ukraine. growth in Ukraine were studied by V. Geets, D. Ogol, Z. Popovych, L. Simkiv, N. Skrypnyk, A. Bulygina and others.

The rapid development of the international economy, uncontrolled consumption of natural resources and damage to the environment have shown that linear development on a permanent basis carries significant environmental and resource problems not only for the individual country, but also for humanity as a whole. That 
is why, from the second half of the 20th century, the developed countries of the world began to introduce radical changes in the concept of longterm economic growth on the basis of circular development. Such a change of priorities provided for the full reproduction of the environment in the course of social production, through the rational use of nature and the introduction of a closed cycle in the consumption of material resources through the reuse of waste. Recognition of the ecological component as the main condition for further development and the need to implement the principles of circular economy was also noted in the works by N. Gakhovych, T. Logutova, O. Poltoratskaya, L. Sergienko-Berdyukova and other researchers.

Given the above, the purpose of this work is to study the development of the national economy in recent years, taking into account the environmental component.

\section{Analysis of gross regional product}

The period of 2015-2018 was chosen for research as it was characterized by the resumption of gradual economic growth in most sectors of the economy after the deep crisis of 2014. It should also be noted that the available data of the State Statistics Service of Ukraine for 2019 do not contain the current moment of complete information on the amount of anthropogenic impact.

It is known from macroeconomics that the generalizing indicator of economic growth of any country is the volume of gross domestic product (GDP) and the average annual growth rate. In Ukraine, during 2015-2018, it increased from 1979458 million UAH up to 3558706 million UAH at actual prices each year. Accordingly, the average annual growth rate, minus the inflation factor, was $+2.8 \%$, which was positive.

However, Ukraine's economy is characterized by uneven territorial development due to differences in natural and climatic conditions, the available raw material base and the structure and distribution of social production. This is evidenced by data on the volume of gross regional product (GRP) in 2018, which are graphically shown in Figure 1. Here all areas are arranged in descending order of the target.

As we can see, the largest GRP in the amount of 833069 million UAH was produced in Kyiv, which accounted for more than $23 \%$ of the country's GDP. Together with Dnipropetrovsk, Kharkiv, Kyiv and Donetsk regions, about 51\% of the gross product was produced here. The contribution of other regions to the economic growth of the state was much smaller. Thus, the worst situation occurred in Chernivtsi (33,903 million UAH), Luhansk $(35,206$ million UAH), Ternopil (49,133 million UAH), Zakarpattia (52,455 million UAH) and Kherson $(55,161$ million UAH) areas. Their total contribution to the formation of the country's GDP in 2018 was about $6 \%$. Thus, it is possible to state significant differences in social development in the context of a regional feature.

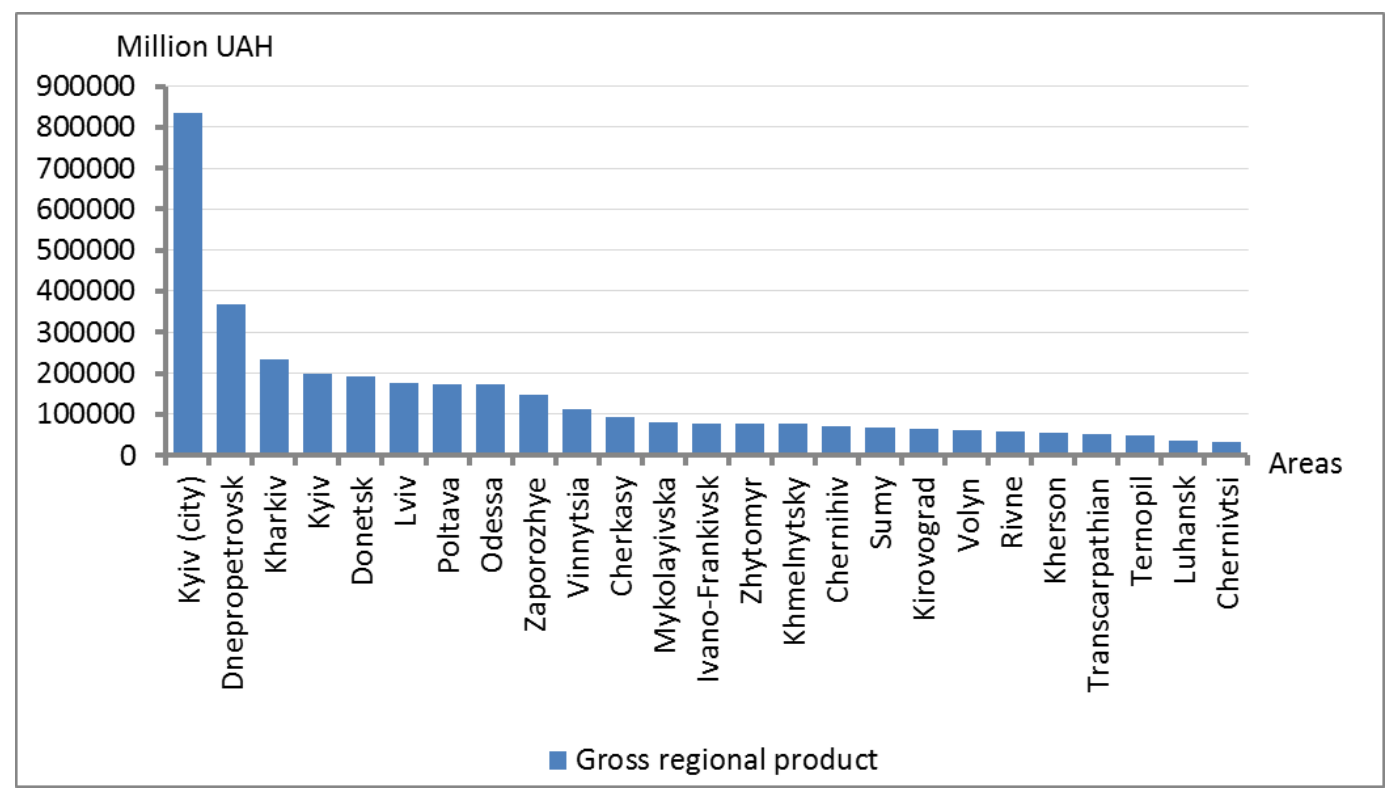

Figure 1. The volume of gross regional product in 2018 


\section{Analysis of the dynamics} of the national economy

To analyze the dynamics of the national economy in 2015-2018, the following factor model was used in this study:

$$
G R P^{i}=P^{i}+G R P^{P, i},
$$

where $G R P^{i}, G R P^{P, i}$ is, accordingly, the annual volume of gross regional product and per capita in the $\mathrm{i}$-th region; $P^{i}$ is the average annual population of the i-th region.

The average annual population is an extensive factor in economic development. In accordance, GRP per capita is a qualitative factor that depends on the productivity of labor resources of a particular region and their share in the total.

To investigate the influence of factors on the performance indicator according to [9], you can use the index method of general statistical theory:

$$
\frac{G R P^{1}}{G R P^{0}}=\frac{P^{1}}{P^{0}} \times \frac{G R P^{P, 1}}{G R P^{P, 0}},
$$

Table 1

The results of the factor analysis of the average annual growth

\begin{tabular}{|c|c|c|c|}
\hline Regions & $\begin{array}{c}\text { Average GRP growth rate, } \\
\%\end{array}$ & $\begin{array}{c}\text { The average growth rate } \\
\text { of GRP per capita, } \%\end{array}$ & $\begin{array}{c}\text { The average growth rate } \\
\text { of } \mathrm{P}, \%\end{array}$ \\
\hline 1 & 2 & 3 & 4 \\
\hline On average in Ukraine & $+2.77 \%$ & $+3.23 \%$ & $-0.46 \%$ \\
\hline Volyn & $+5.72 \%$ & $+5.92 \%$ & $-0.18 \%$ \\
\hline Kyiv & $+5.66 \%$ & $+5.03 \%$ & $+0.55 \%$ \\
\hline Zhytomyr & $+5.00 \%$ & $+5.70 \%$ & $-0.72 \%$ \\
\hline Kyiv (city) & $+4.96 \%$ & $+4.40 \%$ & $+0.54 \%$ \\
\hline Vinnytsia & $+4.38 \%$ & $+5.22 \%$ & $-0.79 \%$ \\
\hline Khmelnytskyi & $+4.28 \%$ & $+5.02 \%$ & $-0.71 \%$ \\
\hline Ivano-Frankivsk & $+3.84 \%$ & $+4.04 \%$ & $-0.17 \%$ \\
\hline Kirovohrad & $+3.47 \%$ & $+4.37 \%$ & $-0.91 \%$ \\
\hline Odesa & $+3.39 \%$ & $+3.56 \%$ & $-0.17 \%$ \\
\hline Lviv & $+2.87 \%$ & $+3.03 \%$ & $-0.16 \%$ \\
\hline Cherkasy & $+2.81 \%$ & $+3.81 \%$ & $-0.92 \%$ \\
\hline Mykolaiv & $+2.53 \%$ & $+3.33 \%$ & $-0.72 \%$ \\
\hline Chernivtsi & $+2.44 \%$ & $+2.64 \%$ & $-0.15 \%$ \\
\hline Ternopil & $+2.42 \%$ & $+2.99 \%$ & $-0.57 \%$ \\
\hline Chernihiv & $+2.29 \%$ & $+3.49 \%$ & $-1.20 \%$ \\
\hline Kharkiv & $+1.93 \%$ & $+2.43 \%$ & $-0.51 \%$ \\
\hline Rivne & $+1.72 \%$ & $+1.82 \%$ & $-0.08 \%$ \\
\hline Zakarpattia & $+1.42 \%$ & $+1.49 \%$ & $-0.05 \%$ \\
\hline Kherson & $+1.13 \%$ & $+1.83 \%$ & $-0.72 \%$ \\
\hline Zaporizhzhia & $+1.09 \%$ & $+1.96 \%$ & $-0.86 \%$ \\
\hline Dnipropetrovsk & $+0.95 \%$ & $+1.42 \%$ & $-0.54 \%$ \\
\hline Sumy & $+0.70 \%$ & $+1.63 \%$ & $-0.95 \%$ \\
\hline Poltava & $-0.51 \%$ & $+0.32 \%$ & $-0.85 \%$ \\
\hline Luhansk & $-0.84 \%$ & $-0.03 \%$ & $-0.78 \%$ \\
\hline Donetsk & $-1.86 \%$ & $-1.06 \%$ & $-0.77 \%$ \\
\hline
\end{tabular}
of gross regional product during 2015-2018 
Cherkasy (-0.92\%) and Kirovohrad (-0.91\%) regions. Given that $\mathrm{CHN}$ is an important factor in regional development, formula (1), the social sphere needs state support, and demographic policy should promote natural population growth.

The average growth of gross regional product at the level of $+2.77 \%$ was provided by the annual growth of GRP per capita by $+3.23 \%$, respectively, the demographic factor had the opposite effect. According to Table 1, the leaders of regional development in terms of GRP growth in 2015-2018 were: Volyn (+ 5.72\%), Kyiv (+5.66\%) and Zhytomyr $(+5.00 \%)$ regions. In contrast, the most depressed regions with negative economic growth rates were: Donetsk (-1.86\%), Luhansk $(-0.84 \%)$ and Poltava $(-0.51 \%)$ regions. In the latter region, the rate of population decline exceeded the increase in labor productivity, resulting in a decrease in performance.

Statistical dependence between the current level of economic development, Figure 1, and the growth rate of GRP, column (2) Table 1, according to the calculation of the corresponding correlation coefficient, was not detected.

The analysis of statistical data (Statistical collection "Regions of Ukraine for 2018. Part 1") shows that one of the priorities of state regulation should be the fight against poverty. Thus, according to 2018, the share of the population with total income lower than the actual subsistence level reached $27.6 \%$. For comparison, in 2015 this figure was $51.9 \%$. Thus, economic growth, first of all, should be transformed into improving the quality of life.

Confirmation of this conclusion is a comparison of annual expenditures per capita and their income. According to calculations, in 2018 in Ukraine, the average costs exceeded the corresponding revenues by $+30.8 \%$. Sources of funding for such excessive expenditures were savings from previous years, unaccounted for income from work abroad, and borrowed funds. The largest differences took place in Kyiv (+ 62.4\%), Chernivtsi (+ 55.3\%), Kharkiv $(+53.8 \%)$, and Zakarpattia $(+50.0 \%)$ regions.

To model the income level of the population, this study found that they had a high direct correlation with the volume of gross regional product per capita. The corresponding correlation coefficient according to 2018 took the value of $\mathrm{R}=0.963$. With this in mind, we have constructed a regression dependence of the linear type, which has the form:

$$
I^{P, i}=24216,5891+0,4073 \times G R P^{P, i} \text {, }
$$

where $I^{P, i}$ - the estimated value of annual disposable income per capita in the i-th region.

In addition to the linear form of dependence, the logarithmic, polynomial, exponential and power regressions were checked, from which the most adequate one was chosen. Verification of compliance of the constructed model (3) with the input data was performed using Fisher's test. It is obtained that the inequality is satisfied with $95 \%$ reliability: $(\mathrm{F}=292.5)>\left(\mathrm{F}_{\text {tabl }}=4.3\right)$. This means that equation (3) describes the initial data well and can be used in further calculations.

$(\mathrm{F}=292.5)>\left(\mathrm{F}_{\mathrm{tabl}}=4.3\right)$. This means that equation (3) describes the initial data well and can be used in further calculations.

Earlier it was mentioned about the priority of the environmental component as the main condition for economic development in the long run. To this end, according to $[10]$, we calculated the average annual growth rate of major types of environmental pollution during 2015-2018 (Table 2).

\section{Conclusions}

Given that the average annual economic growth rate in Ukraine during the study period was $+2.77 \%$

Table 2

Calculation of the average annual growth rate of environmental pollution in 2015-2018

\begin{tabular}{|l|c|c|c|c|c|}
\hline \multicolumn{1}{|c|}{ Types of environmental pollution } & 2015 & 2016 & 2017 & 2018 & $\overline{T_{\Pi P}}, \%$ \\
\hline \multicolumn{1}{|c|}{1} & 2 & 3 & 4 & 5 & 6 \\
\hline $\begin{array}{l}\text { Volumes of atmospheric emissions } \\
\text { of pollutants, thousand tons }\end{array}$ & 2857.4 & 3078.1 & 2584.9 & 2508.3 & $-4.25 \%$ \\
\hline $\begin{array}{l}\text { Volumes of atmospheric emissions of carbon } \\
\text { dioxide, thousand tons }\end{array}$ & 138932.1 & 150581.0 & 124217.9 & 126378.3 & $-3.11 \%$ \\
\hline $\begin{array}{l}\text { Waste generation from economic activity, } \\
\text { thousand tons }\end{array}$ & 306214.3 & 289523.6 & 360196 & 346790.4 & $+4.24 \%$ \\
\hline Fresh water intake by enterprises, million $\mathrm{m}^{3}$ & 9109 & 9325 & 8635 & 10705 & $+5.53 \%$ \\
\hline Use of fresh water by enterprises, million $\mathrm{m}^{3}$ & 6556 & 6608 & 6284 & 6790 & $+1.18 \%$ \\
\hline
\end{tabular}


(Table 1), the results of environmental measures can be classified as follows:

- in the conditions of positive rates of economic development, the volumes of atmospheric emissions of pollutants and carbon dioxide had a negative dynamics. This scenario of environmental and economic efficiency is the most desirable;

- positive growth rates of fresh water use were inferior to GDP growth rates. This indicates, firstly, the growing dependence of the economy on this type of natural resources in quantitative terms, secondly, the increasing efficiency of its use;

- the rate of waste generation and economic abstraction exceeded the dynamics of GDP growth. This scenario is the least acceptable, as not only is environmental damage increasing in absolute terms, but environmental performance is also deteriorating.

\section{References:}

Geets, V. M. (2000). Instability and economic growth. Kyiv, 344 p.

Ogol, D. O. (2015). Economic growth: essence, quality and sustainability. Actual problems of economy, vol.2, pp. 67-72. Access mode: http://nbuv.gov.ua/UJRN/ape_2015_2_11

Popovych, Z. (2016). Economic growth and prospects for innovative development. Economy of Ukraine, vol. 12, pp. 41-48.

Simkiv, L. E. (2014). Qualitative economic growth in Ukraine, its assessment and ways of providing. Innovative economy, vol. 2, pp. 21-25. Access mode: http://nbuv.gov.ua/UJRN/inek_2014_2_4

Skrypnyk, N. E., \& Bulygina, A. V. (2017). Factors and preconditions of economic growth in Ukraine. Eastern Europe: Economics, Business and Management, vol. 6, pp. 11-15.

Gakhovich, N. G. (2012). Ecologization of industrial production as a necessary condition for overcoming disproportion. World economic disproportion: features, tendencies, influence on the economy of Ukraine: scientific report / ed. Corresponding Member NAS of Ukraine L. V. Shinkaruk; NAS of Ukraine, Inst. of Economics and predicted. NAS of Ukraine. Kyiv, pp. 94-98.

Logutova, T. G., \& Poltoratska, O. V. (2012). The problem of resource provision in the world economy. Theoretical and practical aspects of economics and intellectual property: a collection of scientific papers: in 2 issues; PDTU. Mariupol, vol. 1, no. 1, pp. 205-211.

Sergienko-Berdyukova, L. V. (2015). Prerequisites for the formation and implementation of the concept of circular economy. Problems, theories and methodologies of accounting, control and analysis, vol. 3(33), pp. 327-350.

Statistical collection "Regions of Ukraine for 2018. Part 1". State Statistics Service of Ukraine. Kyiv, 2019. 309 p.

Statistical collection "Environment of Ukraine for 2018". State Statistics Service of Ukraine. Kyiv, 2019. 214 p. 